\title{
Impaired Microvascular Reactivity and Endothelial Function in Patients with Cushing's Syndrome: Influence of Arterial Hypertension
}

\author{
M. PRÁZNÝ ${ }^{1}$, J. JEŽKOVÁ ${ }^{1}$, E. HOROVÁ ${ }^{1}$, V. LAZÁROVÁ ${ }^{1}$, V. HÁNA ${ }^{1}$, J. KVASNIČKA ${ }^{2}$, \\ L. PECEN ${ }^{3}$, J. MAREK ${ }^{1}$, J. ŠKRHA ${ }^{1}$, M. KRŠEK ${ }^{1}$ \\ ${ }^{1}$ Third Department of Internal Medicine, First Faculty of Medicine, Charles University, Prague, \\ Czech Republic, ${ }^{2}$ First Department of Internal Medicine, First Faculty of Medicine, Charles \\ University, Prague, and ${ }^{3}$ Institute of Informatics, Czech Academy of Sciences, Prague, Czech \\ Republic
}

Received January 25, 2006

Accepted December 19, 2006

On-line available January 2, 2007

\begin{abstract}
Summary
The aim of the study was to evaluate skin microvascular reactivity (MVR) and possible influencing factors (fibrinolysis, oxidative stress, and endothelial function) in patients with Cushing's syndrome. Twenty-nine patients with active Cushing's syndrome (ten of them also examined after a successful operation) and 16 control subjects were studied. Skin MVR was measured by laser Doppler flowmetry during post-occlusive (PORH) and thermal hyperemia (TH). Malondialdehyde and $\mathrm{Cu}, \mathrm{Zn}$-superoxide dismutase were used as markers of oxidative stress. Fibrinolysis was estimated by tissue plasminogen activator (tPA) and its inhibitor (PAI- 1 ). N-acetyl- $\beta$-glucosaminidase, E-selectin, P-selectin, and ICAM-1 were used as markers of endothelial function. Oxidative stress and endothelial dysfunction was present in patients with hypercortisolism, however, increased concentration of ICAM-1 was also found in patients after the operation as compared to controls (290.8 \pm 74.2 vs. $\left.210.9 \pm 56.3 \mathrm{ng} \cdot \mathrm{ml}^{-1}, \mathrm{p}<0.05\right)$. Maximal perfusion was significantly lower in patients with arterial hypertension during PORH and $\mathrm{TH}$ ( $36.3 \pm 13.0$ vs. $63.3 \pm 32.4 \mathrm{PU}, \mathrm{p}<0.01$, and $90.4 \pm 36.6$ vs. $159.2 \pm 95.3 \mathrm{PU}, \mathrm{p}<0.05$, respectively) and similarly the velocity of perfusion increase during PORH and TH was lower (3.2 \pm 1.5 vs. $5.2 \pm 3.4$ PU. $\mathrm{s}^{-1}, \mathrm{p}<0.05$, and $0.95 \pm 0.6$ vs. $1.8 \pm 1.1 \mathrm{PU}^{-1} \mathrm{~s}^{-1}$, $\mathrm{p}<0.05$, respectively). The most pronounced impairment of microvascular reactivity was present in patients with combination of arterial hypertension and diabetes mellitus.
\end{abstract}

\section{Key words}

Cushing's syndrome • Vascular reactivity • Endothelial function • Oxidative stress $\bullet$ Laser Doppler flowmetry

\section{Corresponding author}

Martin Prázný, Third Department of Internal Medicine, First Faculty of Medicine, U nemocnice 1, 12808 Prague 2, Czech Republic. Fax: +420224962463, E-mail: mpra@LF1.cuni.Cz

\section{Introduction}

It is well known that hypercortisolism is associated with increased morbidity and mortality caused predominantly by vascular and atherosclerotic complications. Cushing's disease, a rare endocrine disorder with prevalence approximately 3.9 cases per 100,000 people and estimated incidence 0.24 cases per 100,000 people per year (Etxabe and Vazquez 1994), represents about $70 \%$ of all endogenous hypercortisolisms (Cushing's syndrome). Patients with untreated Cushing's syndrome have cardiovascular mortality four to five times higher than normal population and their cardiovascular risk is significantly increased (Etxabe and Vazquez 1994, Mancini et al. 2004). However, patients with cured Cushing's syndrome also have an increased prevalence of atherosclerosis even several years after normalization of hypercortisolism (Colao et al. 1999, Faggiano et al. 2003). The effect of hypercortisolism on microvasculature is less known. The aim of this study was to measure the microvascular reactivity using laser Doppler flowmetry method and evaluate endothelial function in patients with Cushing's syndrome. Selected parameters of fibrinolysis and oxidative stress were also determined. The results were compared to the control group and also to a subgroup of patients with cured hypercortisolism.

Laser Doppler flowmetry is an easy and noninvasive method for testing skin microvascular reactivity (Yvonne-Tee et al. 2006). This method uses laser beam 
and fiber optics probes for detection of blood flow in small vessels located in adjacent layers of the tissue and can be used in many practical and experimental applications. These include transplantations, plastic surgery and also observation of drug effects (Binggeli et al. 2003, Štulc et al. 2003). Combination of laser Doppler flowmetry with an assay of biochemical markers of endothelial dysfunction, oxidative stress, and fibrinolysis can bring up additional information on vascular changes. Detection of possible changes in endothelial function and in microvascular reactivity can contribute to the understanding of mechanisms of vascular impairment in hypercortisolism.

\section{Methods}

\section{Patients}

Twenty-nine patients with hypercortisolism (8 men, 21 women, 21-60 years) were included in the study (group HC, hypercortisolism). The cause of hypercortisolism was pituitary adenoma (Cushing's disease) in 22 patients, adrenal cortex adenoma in 6 patients, and an ectopic production of ACTH in one patient. Patients with Cushing's syndrome were characterized by typical clinical features of Cushing's syndrome, elevated urinary free cortisol excretion (UFC), blunted circadian variability of plasma cortisol levels with elevated midnight cortisol levels and lack of appropriate suppression in the low-dose dexamethasone suppression test (LDDST - overnight variant with $1 \mathrm{mg}$ of dexamethasone given at 23:00 h.). The diagnosis of pituitary or adrenal cortex adenoma was verified by histological examination. Fifteen patients (52\%) from this group had diabetes mellitus, eleven of them (38\%) were on diet only or treated with oral antidiabetic drug(s), four $(14 \%)$ were treated with insulin. We did not exclude diabetic patients from the study because secondary diabetes mellitus is a common and inseparable feature of clinically expressed hypercortisolism. Furthermore, patients treated with insulin did not differ significantly from the rest of the group in measured parameters and we also decided not to exclude them. 17 patients (59\%) had arterial hypertension and were treated with antihypertensive drugs. Only one patient had coronary heart disease with angina pectoris in his medical history.

Ten patients from this group (4 men, 6 women, 24-59 years) have been successfully treated by surgery and examined also after 6 to 24 months (mean $16 \pm 6$ months) when cortisol levels were fully normalized (group NC, normalized cortisol). This satisfactory treatment was characterized by normal 24-h urinary free cortisol excretion, by recovered circadian variability of plasma cortisol levels, and by suppressibility of plasma cortisol after an overnight dexamethasone $(1 \mathrm{mg})$ test with $08.00 \mathrm{~h}$ cortisol level below $84 \mathrm{nmol} / \mathrm{l}$. No patients from $\mathrm{NC}$ group had diabetes or arterial hypertension present at the time of the second examination.

Another 16 healthy sex-, age-, and BMI-matched subjects (4 men, 12 women, 29-62 years) served as the control group (group C). The control subjects participated on voluntary basis and were recruited from non-obese hospital workers and from otherwise healthy obese subjects not enrolled in another study or a weight reduction program. The characteristics of all subjects are shown in Table 1. Study was approved by the Ethical Committee of First Faculty of Medicine, Charles University, and all subjects gave their written informed consent.

\section{Biochemical methods}

Plasma cortisol levels were determined with RIA kit (Immunotech, France) with intra-assay variability $5.1 \%$ and inter-assay variability $9.2 \%$. Urinary free cortisol (UFC) was determined by the same RIA kit. Serum insulin concentration was measured by RIA kits (Pharmacia-Upjohn Diagnostics, Sweden). Insulin resistance was assessed by the HOMA-R index calculated from fasting blood glucose (G) and insulin (I) concentrations using the formula: $\left(\mathrm{G}^{*} \mathrm{I}\right) / 22.5$ (Matthews et al. 1985).

Total serum cholesterol (TC), HDL- and LDLcholesterol (HDL-C, LDL-C), and triglycerides (TG) were measured by routine methods on Hitachi analyzer. Glycated hemoglobin $\mathrm{HbA}_{1 \mathrm{C}}$ was analyzed with the Imx Ghb Assay system on Abbot analyzer (USA) using DCCT calibration. Plasma glucose was measured by standard glucose oxidase method on the Super GL ambulance analyzer (Dr. Müller Gerätebau, Germany). $\mathrm{Cu}, \mathrm{Zn}$-superoxide dismutase activity (SOD) in erythrocytes (EC 1.15.1.1.) was evaluated in the xanthine-xanthine oxidase system on spectrophotometer Genesys 5, USA (McCord and Fridovich 1969). Plasma malondialdehyde (MDA) concentration was measured by fluorimetric method (Yagi 1976). Fibrinolysis was characterized by plasma concentrations of tissue plasminogen activator (tPA) and its inhibitor (PAI-1) and determined by ELISA method using Coalisa tPA and PAI-1 commercial kits (KABI Diagnostics, Sweden). 
Table 1. Characteristic of patients with hypercortisolism (HC), normalized cortisol secretion after treatment (NC) and control subjects (C).

\begin{tabular}{|c|c|c|c|}
\hline & HC $(n=29)$ & $N C(n=10)$ & $C(n=16)$ \\
\hline Age (years) & $47 \pm 12$ & $45 \pm 11$ & $48 \pm 11$ \\
\hline Gender $(M / F)$ & $8 / 21$ & $4 / 6$ & $4 / 12$ \\
\hline$B M I\left(k g \cdot m^{-2}\right)$ & $31.30 \pm 7.07$ & $27.97 \pm 8.09$ & $28.66 \pm 3.52$ \\
\hline$f P$-glucose $\left(\right.$ mmol. $\left.^{-1}\right)$ & $7.55 \pm 3.75$ & $5.27 \pm 0.73$ & $5.16 \pm 0.24$ \\
\hline$H b A_{l C}(\%)$ & $7.5 \pm 1.8^{\mathrm{x}}$ & $5.8 \pm 1.3$ & $4.7 \pm 0.3$ \\
\hline$U F C(n m o l / 24 h)$ & $1702.8 \pm 2709.5^{\mathrm{x}, \mathrm{c}}$ & $146.8 \pm 110.1$ & $186.0 \pm 79.9$ \\
\hline midnight plasma cortisol $\left(\right.$ nmol. $\left.l^{-1}\right)$ & $682.9 \pm 353.8^{\mathrm{x}, \mathrm{c}}$ & $94.8 \pm 38.2$ & - \\
\hline fP-cortisol in LDDST (nmol. $\left.l^{-1}\right)$ & $728.2 \pm 369.1^{\mathrm{x}, \mathrm{c}}$ & $47.6 \pm 16.2$ & $53.9 \pm 12.5$ \\
\hline$f S-T C\left(\right.$ mmol. $\left.l^{-1}\right)$ & $7.22 \pm 1.67^{\mathrm{y}, \mathrm{c}}$ & $5.35 \pm 0.50$ & $5.38 \pm 0.78$ \\
\hline$f S-H D L-C\left(m_{m o l} l^{-1}\right)$ & $1.44 \pm 0.27^{b}$ & $1.27 \pm 0.34$ & $1.19 \pm 0.21$ \\
\hline$f S-L D L-C\left(\right.$ mmol. $\left.l^{-1}\right)$ & $4.28 \pm 1.27^{\mathrm{x}, \mathrm{b}}$ & $3.29 \pm 0.39$ & $3.44 \pm 0.67$ \\
\hline$f S-T G\left(m m o l . l^{-1}\right)$ & $2.89 \pm 1.26^{b}$ & $1.94 \pm 1.28$ & $1.66 \pm 0.94$ \\
\hline$f S$-Insulin $\left(m U . l^{-1}\right)$ & $35 \pm 24^{\mathrm{c}}$ & $21 \pm 5$ & $16 \pm 12$ \\
\hline$H O M A-R$ & $12.20 \pm 12.58$ & $4.60 \pm 1.45$ & $3.4 \pm 1.9$ \\
\hline $\mathrm{SBP}(\mathrm{mm} \mathrm{Hg})$ & $148 \pm 21^{\mathrm{c}}$ & $133 \pm 10^{\mathrm{a}}$ & $122 \pm 6$ \\
\hline$D B P(m m H g)$ & $92 \pm 13^{\mathrm{c}}$ & $82 \pm 8$ & $77 \pm 6$ \\
\hline
\end{tabular}

Fasting plasma (fP) or fasting serum (fS) samples were used for analysis. Significant differences: between groups $\mathrm{HC}$ and $\mathrm{NC} \times \mathrm{p}<0.05$, ${ }^{y} p<0.01$; between groups $\mathrm{HC}$ or NC and control group (C) ${ }^{a} p<0.05,{ }^{b} p<0.01,{ }^{c} p<0.001$.

Table 2. Parameters of oxidative stress, endothelial function, fibrinolysis and microvascular reactivity in patients with hypercortisolemia (HC), normalized cortisol secretion after treatment (NC) and control subjects (C).

\begin{tabular}{|c|c|c|c|}
\hline & HC $(n=29)$ & $\mathrm{NC}(\mathrm{n}=10)$ & $C(n=16)$ \\
\hline$f P-M D A\left(\mu m o l .1^{-1}\right)$ & $2.71 \pm 0.61^{\mathrm{x}, \mathrm{b}}$ & $2.07 \pm 0.28$ & $2.14 \pm 0.37$ \\
\hline$C u, Z n-S O D(U)$ & $0.88 \pm 0.29^{c}$ & $0.95 \pm 0.18^{b}$ & $1.31 \pm 0.13$ \\
\hline$f P-t P A\left(n g \cdot m l^{-1}\right)$ & $7.87 \pm 3.43^{\mathrm{x}, \mathrm{a}}$ & $4.47 \pm 2.72$ & $4.36 \pm 1.57$ \\
\hline$f P-P A I-I\left(n g . m l^{-1}\right)$ & $80.83 \pm 33.42$ & $76.88 \pm 33.50$ & $99.19 \pm 32.29$ \\
\hline$f P-N A G\left(U . I^{-1}\right)$ & $22.92 \pm 7.74$ & $21.19 \pm 6.06$ & $18.66 \pm 5.92$ \\
\hline$f S-E$-selectin $\left(n g \cdot m l^{-1}\right)$ & $47.65 \pm 23.27$ & $57.28 \pm 26.18$ & $41.36 \pm 14.18$ \\
\hline$f S$-P-selectin $\left(n g . m l^{-1}\right)$ & $169.00 \pm 63.60$ & $175.17 \pm 62.08$ & $132.02 \pm 47.22$ \\
\hline$f S-I C A M-1\left(n g . m l^{-1}\right)$ & $227.40 \pm 67.13^{\mathrm{x}, \mathrm{b}}$ & $290.84 \pm 74.22^{\mathrm{a}}$ & $210.94 \pm 56.33$ \\
\hline PORHmax (PU) & $46.30 \pm 25.39^{a}$ & $59.02 \pm 35.56$ & $64.25 \pm 24.97$ \\
\hline PORHmax/t (PU/s) & $3.95 \pm 2.53$ & $4.08 \pm 3.41$ & $5.41 \pm 2.89$ \\
\hline PORH\% $(\%)$ & $441.33 \pm 265.64$ & $469.90 \pm 285.47$ & $591.31 \pm 194.53$ \\
\hline$T H \max (P U)$ & $115.89 \pm 71.51^{\mathrm{a}}$ & $144.11 \pm 73.80$ & $171.63 \pm 68.06$ \\
\hline$T H \max / t(P U / s)$ & $1.27 \pm 0.90^{\mathrm{b}}$ & $1.66 \pm 0.76$ & $2.30 \pm 1.39$ \\
\hline$T H \%(\%)$ & $1305.37 \pm 815.71$ & $1281.70 \pm 515.77$ & $1768.06 \pm 628.07$ \\
\hline
\end{tabular}

Fasting plasma (fP) or fasting serum (fS) samples were used for analysis. Significant differences: between groups $\mathrm{HC}$ and $\mathrm{NC} \times \mathrm{p}<0.05$, ${ }^{y} \mathrm{p}<0.01$; between groups HC or NC and control group (C) ${ }^{a} p<0.05,{ }^{b} p<0.01,{ }^{c} p<0.001$.

Serum N-acetyl- $\beta$-glucosaminidase activity (NAG, EC 3.2.1.30), E-selectin, P-selectin, and ICAM-1 were used as biochemical markers of endothelial activity and these cell adhesion molecules were assessed by commercial ELISA kits manufactured by RD System Europe, Ltd. (UK). Serum NAG was determined by 
spectrophotometric assay using p-nitrophenyl-N-acetyl- $\beta$ D-glucosaminide (Sigma, USA) as a substrate (Škrha et al. 1987). Immunoassays had an intraassay variability below $5 \%$ and interassay variability below $8 \%$. All samples from the patients were measured in one assay to minimize the effect of variation.

\section{Microvascular reactivity}

Skin microvascular reactivity (MVR) was measured by laser Doppler flowmetry using a PeriFlux PF 4001 Master laser instrument and a PeriTemp 4001 Heater thermostatic unit manufactured by Perimed (Sweden). Instrument settings were as follows: time constant $0.02 \mathrm{~s}$, sampling frequency $32 \mathrm{~Hz}$, averaging from two samples. Measurements were done at a room temperature of $22{ }^{\circ} \mathrm{C}$ in a sitting position, and all subjects rested for at least $30 \mathrm{~min}$ in order to acclimatize before examination. Post-occlusive reactive hyperemia (PORH) and thermal hyperemia $(\mathrm{TH})$ tests were chosen for the assessment of microvascular reactivity. A single thermostatic probe (type 455, $23 \mathrm{~mm}$ diameter, fiber separation $0.25 \mathrm{~mm}$ ) was used for both tests. Optical fibers in this probe are integrated into the heating plate and thus the entire area of tissue under the probe is heated. The probe was fixed with double-stick discs $(3 \mathrm{M}$, USA) to the forearm and its temperature was set to $32{ }^{\circ} \mathrm{C}$ for the purpose of skin thermal stabilization during PORH. A temperature of $44{ }^{\circ} \mathrm{C}$ was used during TH as the thermal stimulus.

Basal perfusion (PORHb) was measured for 2 min before the PORH test. The brachial artery was then occluded by a sphygmomanometer cuff inflated to a suprasystolic pressure for $3.5 \mathrm{~min}$. The cuff was applied around the arm before the procedure started in order to avoid any extra manipulation with the extremity during the test. PORH was recorded after $3.5 \mathrm{~min}$ of arterial occlusion. Maximal perfusion during hyperemia was recorded (PORHmax) as well as the time needed for reaching this maximal perfusion (PORHt). The velocity of the perfusion increase (PORHmax/t) was calculated as the ratio of PORHmax and PORHt. Relative hyperemia (PORH \%) was calculated as a percent increase above the baseline $($ PORH $\%=($ PORHmax $/$ PORHb -1$) * 100)$.

Thermal hyperemia was measured 10 min after the PORH test at the same location. The probe temperature was set to $44{ }^{\circ} \mathrm{C}$ and parameters THmax, $\mathrm{THt}$, and THmax/t were recorded or calculated similarly as those in the PORH test. TH \% was calculated using formula $\mathrm{TH} \%=(\mathrm{THmax} / \mathrm{PORHb}-1) * 100$. Perfusion is given in arbitrary perfusion units (PU). Perisoft for DOS $5.10 \mathrm{C} 2$ and Perisoft for Windows 2.5 software were used for recording and evaluating perfusion data. Records were blinded and the evaluation was performed by a single operator. The intra-individual coefficient of variation of the laser Doppler method in 5 healthy subjects measured ten times on ten consecutive days varied from 17 to $24 \%$ in TH and 19 to $25 \%$ in PORH, depending on the analyzed parameter.

We did not repeat the examination of MVR in the control group as the effect of time difference in healthy subjects is negligible - about $0.55-0.88$ flow units per year, i.e. estimated $0.4-0.7 \%$ decrease in both resting and stimulated skin blood flow (Petrofsky and Lee 2005).

\section{Statistical evaluation}

Statistical evaluation was performed by S.A.S. 8.2 software. Basic descriptive statistics were calculated for presented parameters. ANOVA, Student's t-test or Wilcoxon's test, Mann-Whitney and KolmogorovSmirnov tests were used for comparing data between groups. Tests were selected depending on normality of data distribution. Pearson's and Spearman's correlations were used for analysis of relationships between measured parameters. Data are expressed as mean \pm S.D. if not stated otherwise.

\section{Results}

Results of BMI, UFC, midnight cortisol and cortisol after LDDST, glucose, $\mathrm{HbA}_{1 \mathrm{C}}$, triglycerides, insulin and HOMA-R are shown in Table 1. As expected, patients with Cushing's syndrome differed significantly from the control group in parameters of cortisol secretion and were typically characterized by significantly elevated urinary free cortisol (UFC, $\mathrm{p}<0.001$ ), plasma midnight cortisol levels $(\mathrm{p}<0.001)$ and abnormal plasma cortisol response after $1.0 \mathrm{mg}$ dexamethasone $(\mathrm{p}<0.001)$ (Table 1). Significantly higher concentrations of lipid parameters were found in $\mathrm{HC}$ group and their decrease to values comparable with the controls was observed after treatment. Significantly higher systolic blood pressure (SBP) and diastolic blood pressure (DBP) was found in $\mathrm{HC}$ group as compared to controls. Patients in NC group had significantly elevated SBP only.

Parameters of fibrinolysis, oxidative stress and endothelial activity are given in Table 2. Plasma MDA was significantly higher in $\mathrm{HC}$ group compared to values after treatment and also compared to control group. 


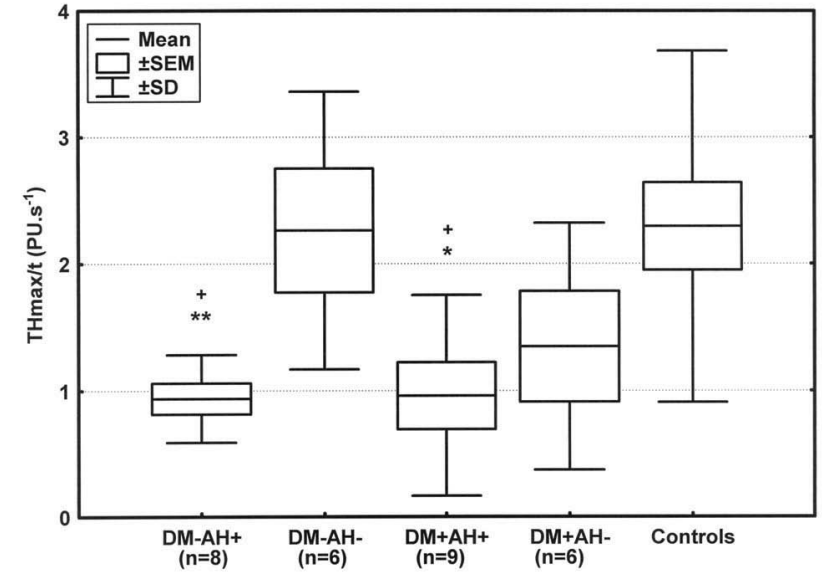

Fig. 1. Comparison of maximal perfusion during thermal hyperemia (THmax) in patients with Cushing's syndrome with and without diabetes mellitus (DM+, DM-) and arterial hypertension $(\mathrm{AH}+, \mathrm{AH}-)$, and control subjects. Statistical significance of differences between $\mathrm{DM}-\mathrm{AH}+$ or $\mathrm{DM}+\mathrm{AH}+$ and controls $\left({ }^{+} p<0.01,{ }^{++} p<0.005\right)$, and $\mathrm{DM}-\mathrm{AH}+$ or $\mathrm{DM}+\mathrm{AH}+$ and DM-AH- $(* \mathrm{p}<0.03, * * \mathrm{p}<0.01)$.

$\mathrm{Cu}, \mathrm{Zn}$-SOD activity was significantly decreased in $\mathrm{HC}$ and $\mathrm{NC}$ groups compared to controls. Plasma tPA was significantly elevated in hypercortisolemic conditions and normalized after the treatment. Concentration of ICAM-1 was higher in both $\mathrm{HC}$ and $\mathrm{NC}$ group when compared to controls. Surprisingly, the highest levels were measured in patients after normalization of cortisol. The difference was also significant when comparing $\mathrm{NC}$ to $\mathrm{HC}$ group. Eand P-selectin concentrations were non-significantly higher in patients with hypercortisolism.

Microvascular reactivity in the examined subjects is shown in Table 2. Microvascular reactivity was significantly diminished in three parameters in group HC compared to controls. A trend towards improvement of MVR could be observed after the normalization of cortisol levels, but these differences did not reach statistical significance when compared to both $\mathrm{HC}$ and control groups.

Patients with hypercortisolism were further subdivided into two groups depending on BMI (cut-off value $30 \mathrm{~kg} \cdot \mathrm{m}^{-2}$ ). In fourteen patients with higher BMI as compared to fifteen patients with lower BMI $(37.3 \pm 5.9$ vs $\left.26.1 \pm 2.1 \quad \mathrm{~kg} . \mathrm{m}^{-2}, \quad \mathrm{p}<0.001\right)$ triglyceride concentration $\left(3.53 \pm 1.39\right.$ vs. $\left.2.30 \pm 0.78 \mathrm{mmol}^{-1} \mathrm{l}^{-1}, \mathrm{p}=0.01\right), \mathrm{NAG}$

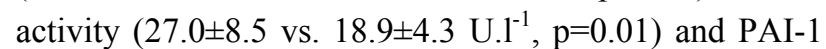
concentration $\quad\left(103.1 \pm 33.9\right.$ vs. $60.6 \pm 15.8 \quad$ ng.ml ${ }^{-1}$, $\mathrm{p}=0.001$ ) were significantly elevated. Furthermore, the results in two subgroups divided according to total cholesterol concentration (cut-off level $6.5 \mathrm{mmol}^{-1} \mathrm{l}^{-1}$ ) were evaluated. Twelve subjects with higher total

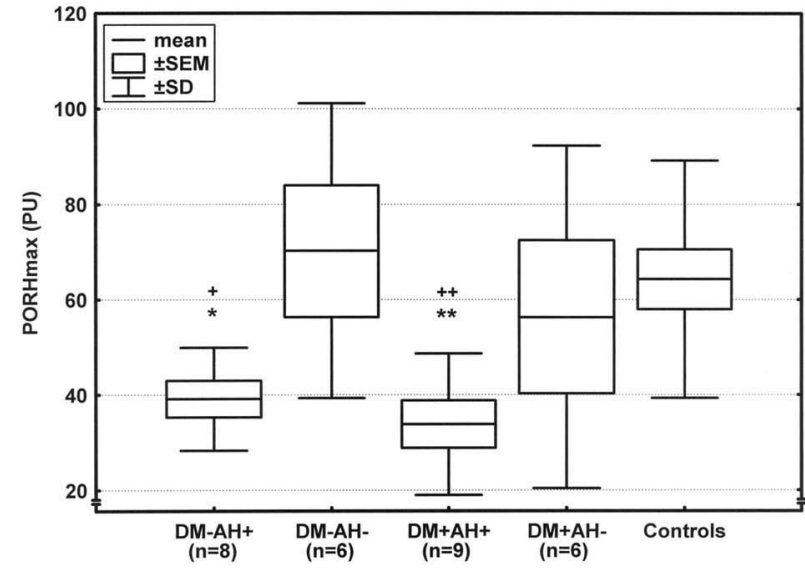

Fig. 2. Comparison of velocity of perfusion increase during thermal hyperemia (THmax/t) in patients with Cushing's syndrome with and without diabetes mellitus (DM+, DM-) and arterial hypertension $(\mathrm{AH}+, \mathrm{AH}-)$, and control subjects. Statistical significance of differences between $\mathrm{DM}-\mathrm{AH}+$ or $\mathrm{DM}+\mathrm{AH}+$ and controls $\left({ }^{+} \mathrm{p}<0.01,{ }^{++} \mathrm{p}<0.005\right)$, and $\mathrm{DM}-\mathrm{AH}+$ or $\mathrm{DM}+\mathrm{AH}+$ and DM-AH- $(* \mathrm{p}<0.03, * * \mathrm{p}<0.01)$.

cholesterol $\left(8.12 \pm 1.51\right.$ vs. $\left.5.81 \pm 0.51 \mathrm{mmol}^{-1}, \mathrm{p}<0.001\right)$ had also significantly higher LDL-cholesterol $(4.92 \pm 1.36$ vs $\left.3.47 \pm 0.47 \mathrm{mmol}^{-1} \mathrm{l}^{-1}, \mathrm{p}=0.01\right)$ and ICAM-1 $(250.2 \pm 74.0$ vs. $192.0 \pm 34.2$ ng. $\mathrm{ml}^{-1}, \mathrm{p}=0.03$ ) than seventeen subjects with lower total cholesterol. Patients in HC group did not differ significantly in any parameter depending on the presence of diabetes mellitus. The only significant difference between diabetic patients treated with insulin and the rest of the HC group was found in PAI-1 (123.5 \pm 30.8 vs. $70.1 \pm 25.2$ ng. $\left.\mathrm{ml}^{-1}, \mathrm{p}<0.01\right)$. However, significant differences were found in parameters of microvascular reactivity between hypercortisolemic patients with and without arterial hypertension, although biochemical parameters were comparable in both subgroups. PORHmax and PORHmax/t were significantly lower in hypertensive than in normotensive patients $(36.3 \pm 13.0$ vs. $63.3 \pm 32.4$ PU, $p<0.01$ and $3.2 \pm 1.5$ vs. $5.2 \pm 3.4$ PU. $\mathrm{s}^{-1}, \mathrm{p}<0.05$, respectively), and similarly THmax and THmax/t (90.4 \pm 36.6 vs. $159.2 \pm 95.3$ $\mathrm{PU}, \mathrm{p}<0.05$, and $0.95 \pm 0.6$ vs. $1.8 \pm 1.1 \mathrm{PU}^{-1}, \mathrm{p}<0.05$, respectively). Comparison of these parameters of microvascular reactivity in hypercortisolemic subjects with respect to the presence of both diabetes mellitus and hypertension is shown in Figures 1,2 and 3.

Subjects in control group were also subdivided based on BMI and TC. Cut-off values were different (BMI $30 \mathrm{~kg} \cdot \mathrm{m}^{-2}$, TC $5.5 \mathrm{mmol.} \mathrm{l}^{-1}$ ) and were set to gain comparable number of subjects in each subgroup. In eight subjects with higher BMI $\left(31.7 \pm 1.7\right.$ vs. $25.6 \pm 1.7 \mathrm{~kg} . \mathrm{m}^{-2}$, $\mathrm{p}<0.001)$ elevated concentration of PAI-1 and ICAM-1 


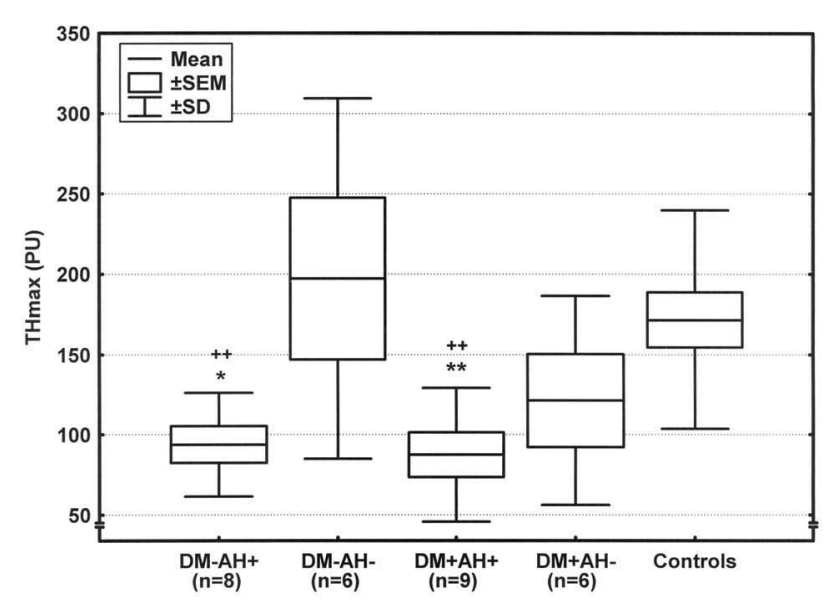

Fig. 3. Comparison of maximal perfusion during post-occlusive reactive hyperemia (PORHmax) in patients with Cushing's syndrome with and without diabetes mellitus (DM+, DM-) and arterial hypertension $(\mathrm{AH}+, \mathrm{AH}-)$, and control subjects. Statistical significance of differences between $\mathrm{DM}-\mathrm{AH}+$ or $\mathrm{DM}+\mathrm{AH}+$ and controls $\left({ }^{+} \mathrm{p}<0.01,{ }^{++} \mathrm{p}<0.005\right)$, and $\mathrm{DM}-\mathrm{AH}+$ or $\mathrm{DM}+\mathrm{AH}+$ and DM-AH- $(* p<0.03, * * p<0.01)$.

was observed $\left(113.7 \pm 17.7\right.$ vs. $62.9 \pm 36.3 \mathrm{ng} \cdot \mathrm{ml}^{-1}, \mathrm{p}=0.04$, and $241.5 \pm 50.1$ vs. $180.4 \pm 46.4 \quad \mathrm{mg} \cdot \mathrm{ml}^{-1}, \mathrm{p}=0.02$, respectively) than in the group of eight subjects with lower BMI. Significantly higher microvascular reactivity (PORH \% 685.5 \pm 135.1 vs. $497.1 \pm 206.3 \%, \mathrm{p}=0.04$ ) was also found in the group with lower BMI. In the subgroup of eight control subjects with higher total cholesterol $\left(6.03 \pm 0.47\right.$ vs. $\left.4.74 \pm 0.39 \mathrm{mmol}^{-1}, \mathrm{p}<0.001\right)$ we have found higher LDL-cholesterol (3.96 \pm 0.41 vs. $2.92 \pm 0.41$ mmol. $\left.1^{-1}, \quad \mathrm{p}<0.001\right)$ and diminished microvascular reactivity in two parameters (PORHmax 52.0 115.3 vs. $76.5 \pm 27.5$ PU, $\mathrm{p}=0.04$, and THmax $137.3 \pm 42.7$ vs. 206.0 $\pm 73.5 \mathrm{PU}, \mathrm{p}=0.03$ ) than in eight subjects with lower total cholesterol.

\section{Correlation analysis}

Patients with hypercortisolism

PAI-1 concentration correlated positively with BMI $\quad(r=0.62, \quad p=0.001), \quad$ triglycerides $\quad(r=0.56$, $\mathrm{p}=0.003)$, serum NAG activity $(\mathrm{r}=0.58, \mathrm{p}=0.008)$ and tPA concentration $(r=0.65, \quad p=0.002)$. Significant positive correlation was found between NAG activity and BMI ( $\mathrm{r}=0.63, \mathrm{p}=0.002)$, whereas inverse relationship was observed between NAG and $\mathrm{Cu}, \mathrm{Zn}-\mathrm{SOD}$ activities $(\mathrm{r}=-0.56, \mathrm{p}=0.02)$ and systolic blood pressure $(\mathrm{r}=-0.59$, $\mathrm{p}=0.005)$. An inverse relationship was found between ICAM-1 and thermal hyperemia expressed in \% (TH \%, $\mathrm{r}=-0.44, \mathrm{p}=0.02)$, whereas ICAM-1 positively correlated with total cholesterol $(\mathrm{r}=0.46, \mathrm{p}=0.02)$ and fasting plasma glucose $(\mathrm{r}=0.58, \mathrm{p}=0.003)$. Malondialdehyde concentration was related to total cholesterol $(r=0.61$, $\mathrm{p}=0.004)$. PORHmax and THmax/t were inversely related to systolic blood pressure $(\mathrm{r}=-0.50, \mathrm{p}=0.009$, and $\mathrm{r}=-0.42, \mathrm{p}=0.03$, respectively).

\section{Normalized cortisol secretion group}

The only significant relationship in this group was observed between ICAM-1 and the velocity of perfusion increase during thermal hyperemia $(r=0.75$, $\mathrm{p}=0.04)$.

\section{Control group}

ICAM-1 concentration correlated significantly with BMI $(r=0.55, p=0.03)$ and triglycerides $(r=0.65$, $\mathrm{p}=0.009)$. Concentration of $\mathrm{P}$-selectin was associated with triglycerides as well $(\mathrm{r}=0.63, \mathrm{p}=0.009)$. Inverse relationship was found between NAG activity and the velocity of perfusion increase during post-occlusive reactive hyperemia $(\mathrm{r}=-0.60, \mathrm{p}=0.02)$. NAG activity was positively associated with tPA concentration $(\mathrm{r}=0.84$, $\mathrm{p}=0.02)$. Malondiadehyde was inversely related to PORHmax/t $\quad(\mathrm{r}=-0.71, \mathrm{p}=0.01)$, THmax $\quad(\mathrm{r}=-0.59$, $\mathrm{p}=0.05)$ and $\mathrm{THmax} / \mathrm{t}(\mathrm{r}=-0.62, \mathrm{p}=0.03)$.

\section{Discussion}

Body weight, lipid parameters, insulin resistance

Total, HDL- and LDL-cholesterol, and triglyceride concentrations were elevated in patients with hypercortisolism. This is a well-known feature of hypercortisolism associated with obesity, decreased sympathetic activity, hyperglycemic effects of cortisol and relative insulinopenia (Friedman et al. 1996). Markedly increased lipolysis in abdominal subcutaneous adipose tissue was demonstrated in patients with Cushing's syndrome using microdialysis method (Kršek et al. 2006). After normalization of cortisol secretion all measured parameters of lipid metabolism decreased and were comparable with control subjects. BMI also decreased after successful treatment, but the difference was not statistically significant. BMI was comparable in all three groups.

Higher serum insulin concentration in hypercortisolemic patients reflects the presence of insulin resistance as documented by increased HOMA-R index. Glucocorticoids increase the insulin resistance and can cause secondary "steroid" diabetes mellitus which is therefore very common in Cushing's syndrome (in our group it was observed in approximately half of patients). 
Insulin resistance declines after normalization of plasma cortisol levels and similarly does insulin concentration. Glucose metabolism usually improves after successful treatment. In current study there were no patients with diabetes 6 to 24 months after normalization of cortisol secretion, and serum insulin concentration and HOMA-R index were comparable with control group.

\section{Fibrinolysis}

Hypercortisolism is associated with changes in fibrinolysis. These changes may also contribute to the development of atherosclerosis (Škrha 2003). Hypercoagulation has been described in patients with Cushing's syndrome and the incidence of flebothrombosis and embolization is increased (Boscaro et al. 2002). This impairment of coagulation process is explained by increased levels of procoagulation factors and depletion of antitrombin-III (Jacoby et al. 2001). In our group only two patients suffered previously from pulmonary embolism. We have examined fibrinolysis by tPA and PAI-1. Plasma tPA concentration was significantly higher in patients with hypercortisolism and positively correlated only with PAI-1 in this group. PAI-1 correlated well with BMI, triglycerides, and NAG in patients with hypercortisolism but not in cured patients or controls. The highest PAI-1 concentrations were found in hypercortisolemic diabetic patients treated with insulin who were obese and had hypercholesterolemia (mean BMI $35 \mathrm{~kg} . \mathrm{m}^{-2}$, mean TC $8.2 \mathrm{mmol}^{-1}$ ). Impaired fibrinolysis is closely related to endothelial dysfunction in different disorders (With et al. 2006) and our findings support the presence of this relationship also in endogenous hypercortisolism. In the control group the relationship between tPA and NAG demonstrates possible association of fibrinolysis with endothelial function in normal conditions as well. We suggest that procoagulation status in Cushing's syndrome may be influenced by increased body weight and disorders of lipid metabolism.

\section{Oxidative stress}

Oxidative stress is one of key factors in development of atherosclerosis (Harrison et al. 2003). Reactive oxygen species and their oxidized products stimulate nuclear factor $\kappa \mathrm{B}(\mathrm{NF}-\kappa \mathrm{B})$ (Aoki et al. 2001), a heterodimeric cytoplasmatic protein. Activated NF- $\kappa \mathrm{B}$ migrates through nuclear membrane, binds to $\kappa \mathrm{B}$ responsive elements and modulates gene transcription. It is followed by endothelial activation, production of cytoadhesive molecules, chemotactic and growth factors. Glucocorticoids inhibit NF- $\kappa \mathrm{B}$ by inducing synthesis of its inhibitor (I $\kappa \mathrm{B})$, decreasing the binding to responsive elements in nucleus and probably also by other mechanisms (Almawi and Melemedjian 2002). Glucocorticoids also inhibit the production of reactive oxygen species in vascular smooth muscle and their effect could be protective (Marumo et al. 1998). On the other hand, obesity, often present in Cushing's syndrome, is associated with increased oxidative stress as described previously (Vincent and Taylor 2005).

In the present study we have measured plasma MDA and activity of $\mathrm{Cu}, \mathrm{Zn}-\mathrm{SOD}$ to estimate oxidative stress. MDA is a product of lipid oxidation and usually it is higher in patients with hypertriglyceridemia (Rumley et al. 2004). As we expected, increased MDA concentration was found in patients with Cushing's syndrome in the present study. We found a relationship between total cholesterol and MDA levels but to our surprise not between triglycerides and MDA. Activity of $\mathrm{Cu}, \mathrm{Zn}-\mathrm{SOD}$ was significantly lower in both groups of patients. $\mathrm{Cu}, \mathrm{Zn}$ SOD was negatively associated with NAG only in HC group suggesting thus a possible influence of oxidative stress on endothelial function in hypercortisolism. A link was suggested also between oxidative stress and arterial hypertension (Landmesser and Harrison 2001). Elevated MDA and lower activity of $\mathrm{Cu}, \mathrm{Zn}$-SOD documents the presence of increased oxidative stress and depleted antioxidative defense in hypercortisolemic subjects. We conclude that hypercortisolism does not inhibit oxidative stress and protective effects of glucocorticoids are suppressed by pro-oxidative processes or insufficient antioxidant mechanisms in patients with Cushing's syndrome.

\section{Endothelial dysfunction}

We used serum NAG activity, P-selectin, E-selectin, and ICAM-1 concentrations as biochemical markers of endothelial dysfunction. Increased ICAM-1 concentration found in patients with hypercortisolism indicates the presence of endothelial dysfunction. In fact, the highest ICAM-1 levels were present in patients with normalized plasma cortisol concentration after successful treatment. It documents the presence of persistent endothelial dysfunction also in cured patients.

NAG, P-selectin, and E-selectin concentrations were comparable with controls, however, higher values of NAG were found in hypercortisolemic subjects with increased BMI. In patients with Cushing's syndrome 
ICAM-1 was significantly higher in patients with increased cholesterol levels rather than in those with increased BMI.

In the control group higher ICAM-1 concentration was present in subjects with higher BMI. Furthermore, in the group of control subjects ICAM-1 and P-selectin levels correlated significantly with triglycerides. These findings indicate the association between endothelial dysfunction, obesity and parameters of lipid metabolism also in normal conditions. Positive relationship between cell adhesion molecules and oxidative stress has been previously discussed (Ceriello et al. 1996, Cominacini et al. 1997). NAG activity is also influenced by oxidative stress (Škrha and Hilgertová 1999). In the present study this association is supported by negative correlation between NAG and $\mathrm{Cu}, \mathrm{Zn}-\mathrm{SOD}$ activity in hypercortisolemic patients. Endothelial dysfunction indicated by NAG and ICAM-1 values in patients with hypercortisolism may therefore also be influenced by oxidative stress.

\section{Microcirculation}

Microvascular reactivity was measured by laser Doppler technique. It is a non-invasive method estimating capillary skin perfusion and can also be used for detection of endothelial dysfunction (Binggeli et al. 2003, Khan et al. 2000, Škrha et al. 2001). Although it is very sensitive, it can be relatively easily influenced by many factors and strictly standard setting of examination is necessary to gain valid results. In the standard conditions it brings consistent and valid data (Yvonne-Tee et al. 2006). In current study we observed impaired maximal perfusion during post-occlusive reactive hyperemia and also during thermal hyperemia in patients with Cushing's syndrome. The velocity of perfusion increase during thermal hyperemia, a dynamic parameter used for assessment of vascular reactivity, was also decreased. These changes indicate the presence of endothelial dysfunction and impaired microvascular reactivity in Cushing's syndrome.

ICAM-1 was inversely related to thermal hyperemia in patients with active Cushing's syndrome. On the contrary, positive relationship between ICAM-1 concentration and the velocity of perfusion increase during thermal hyperemia was detected in subjects with normalized cortisol. In these patients, the highest levels of ICAM-1 were measured. However, no relationship between ICAM-1 and microvascular reactivity was observed in this group either. We can only speculate that increased ICAM-1 levels in this group may reflect intensive reparational changes in circulation after longterm impairment evoked by hypercortisolism and associated comorbidities. In control subjects negative correlation was found between the velocity of perfusion increase during thermal hyperemia and serum NAG activity, and inverse relationships were observed between MDA and three parameters of microvacular reactivity. These were not present in patients with hypercortisolism or in cured patients. Oxidative stress and endothelial dysfunction may thus modulate microvascular reactivity in normal conditions, but other factors are probably more dominant in hypercortisolism.

There are several pathophysiological mechanisms leading to arterial hypertension in patients with Cushing's syndrome, including stimulation of mineralocorticoid and glucocorticoid receptors, insulin resistance, and overexpression of renin-angiotensin system (Sacerdote et al. 2005). Two parameters of MVR correlated negatively with systolic blood pressure in our study. Following this finding, we compared patients with Cushing's syndrome with respect to the presence of diabetes mellitus and arterial hypertension. Both diabetes mellitus and arterial hypertension are associated with endothelial dysfunction (Landmesser and Harrison 2001, Schalkwijk and Stehouwer 2005). In the current study, the most expressed impairment of microvascular reactivity was clearly present in patients with hypertension (Figs 1, 2 and 3). The presence of diabetes mellitus brings an additional statistically nonsignificant impairment to parameters of MVR in THmax and PORHmax. The combination of both these pathological conditions, diabetes mellitus and arterial hypertension, then led to the most decreased microvascular reactivity in patients with Cushing's syndrome.

\section{Conclusions}

In the current study we have found arterial hypertension, insulin resistance, impaired fibrinolysis, increased oxidative stress, endothelial dysfunction and impaired microvascular reactivity in patients with Cushing's syndrome. Based on the obtained results, we conclude that microvascular reactivity can be modulated by many factors in hypercortisolism but the most important is probably the presence of arterial hypertension. Further research in this field and longer observation of larger number of patients with endogenous hypercortisolism is necessary to analyze the association 
between arterial hypertension and macrovascular complications properly. This will probably be complicated by the rarity of this disease. It is not clear whether impaired microcirculation is directly associated with macroangiopathic complications in Cushing's syndrome (and this study cannot answer such question) but if so, strict control of blood pressure could potentially reduce increased cardiovascular morbidity and mortality in patients with Cushing's syndrome.

\section{Conflict of Interest}

There is no conflict of interest.

\section{Acknowledgements}

The study was supported by the grant IGA Ministry of Health Czech Republic NR 8125-3/2004. We want to thank Marcela Jarolímková, Hana Homolková and Jana Pacnerová for excellent technical and laboratory assistance.

\section{References}

ALMAWI WY, MELEMEDJIAN OK: Negative regulation of nuclear factor- $\kappa \mathrm{B}$ activation and function by glucocorticoids. J Mol Endocrinol 28: 69-78, 2002.

AOKI M, NATA T, MORISHITA R, MATSUSHITA H, NAKAGAMI H, YAMAMOTO K, YAMAZAKI K, NAKABAYASHI M, OGIHARA T, KANEDA Y: Endothelial apoptosis induced by oxidative stress through activation of NF- $\mathrm{BB}$ : antiapoptotic effect of antioxidant agents on endothelial cells. Hypertension 38: 48-55, 2001.

BINGGELI C, SPIEKER LE, CORTI R, SUDANO I, STOJANOVIC V, HAYOZ D, LUSCHER TF, NOLL G: Statins enhance postischemic hyperemia in the skin circulation of hypercholesterolemic patients: a monitoring test of endothelial dysfunction for clinical practice? J Am Coll Cardiol 42: 71-77, 2003.

BOSCARO M, SONINO N, SCARDA A, BARZON L, FALLO F, SARTORI MT, PATRASSI GM, GIROLAMI A: Anticoagulant prophylaxis markedly reduces thromboembolic complications in Cushing's syndrome. $J$ Clin Endocrinol Metab 87: 3662-3666, 2002.

CERIELlO A, FALleTi E, BORTOLOTTI N, MOTZ E, CAVARAPE A, RUSSO A, GONANO F, BARTOLI E: Increased circulating intercellular adhesion molecule-1 levels in type II diabetic patients: the possible role of metabolic control and oxidative stress. Metabolism Clin Exp 45: 498-501, 1996.

COLAO A, PIVONELLO R, SPIEZIA S, FAGGIANO A, FERONE D, FILIPPELLA M, MARZULLO P, CERBONE G, SICILIANI M, LOMBARDI G: Persistence of increased cardiovascular risk in patients with cushing's disease after five years of successful cure. J Clin Endocrinol Metab 84: 2664-2672, 1999.

COMINACINI L, FRATTA PASINI A, GARBIN U, CAMPAGNOLA M, DAVOLI A, RIGONI A, ZENTI MG, PASTORINO AM, LO CASCIO V: E-Selectin plasma concentration is influenced by glycaemic control in NIDDM patients: possible role of oxidative stress. Diabetologia 40: 584-589, 1997.

ETXABE J, VAZQUEZ J: Morbidity and mortality in Cushing's disease: an epidemiological approach. Clin Endocrinol (Oxf) 40: 479-484, 1994.

FAGGIANO A, PIVONELLO R, SPIEZIA S, DE MARTINO MC, FILIPPELLA M, Di SOMMA C, LOMBARDI G, COLAO A: Cardiovascular risk factors and common carotid artery caliber and stiffness in patients with Cushing's disease during active disease and 1 year after disease remission. J Clin Endocrinol Metab 88: 2527 2533, 2003.

FRIEDMAN T, MASTORAKOS G, NEWMAN T, MULLEN N, HORTON E, COSTELLO R, PAPADOPOULOS N, CHROUSOS G: Carbohydrate and lipid metabolism in endogenous hypercortisolism: shared features with metabolic syndrome X and NIDDM. Endocr J 43: 645-655, 1996.

HARRISON D, GRIENDLING KK, LANDMESSER U, HORNIG B, DREXLER H: Role of oxidative stress in atherosclerosis. Am J Cardiol 91 (3A): 7A-11A, 2003.

JACOBY R, OWINGS J, ORTEGA T, GOSSELIN R, FELDMAN E: Biochemical basis for the hypercoagulable state seen in Cushing syndrome. Arch Surg 136: 1003-1007, 2001.

KHAN F, ELHADD TA, GREENE SA, BELCH JJF: Impaired skin microvascular function in children, adolescents, and young adults with type I diabetes. Diabetes Care 23: 215-220, 2000. 
KRŠEK M, ROSICKÁ M, NEDVÍDKOVÁ J, KVASNIČKOVÁ H, HÁNA V, MAREK J, HALUZÍK M, LAI EW, PACÁK K: Increased lipolysis of subcutaneous abdominal adipose tissue and altered noradrenergic activity in patients with Cushing's syndrome: an in-vivo microdialysis study. Physiol Res 55: 421-428, 2006.

LANDMESSER U, HARRISON DG: Oxidative stress and vascular damage in hypertension. Coron Artery Dis 12: 455$461,2001$.

MANCINI T, KOLA B, MANTERO F, BOSCARO M, ARNALDI G: High cardiovascular risk in patients with Cushing's syndrome according to 1999 WHO/ISH guidelines. Clin Endocrinol 61: 768-777, 2004.

MARUMO T, SCHINI-KERTH VB, BRANDES RP, BUSSE R: Glucocorticoids inhibit superoxide anion production and p22 Phox mRNA expression in human aortic smooth muscle cells. Hypertension 32: 1083-1088, 1998.

MATTHEWS D, HOSKER J, RUDENSKI A, NAYLOR B, TREACHER D, TURNER R: Homeostasis model assessment: insulin resistance and beta-cell function from fasting plasma glucose and insulin concentrations in man. Diabetologia 28: 412-419, 1985.

MCCORD J, FRIDOVICH I: Superoxide dismutase. J Biol Chem 244: 6049-6055, 1969.

PETROFSKY J, LEE S: The effects of type 2 diabetes and aging on vascular endothelial and autonomic function. Med Sci Monit 11: CR247-254, 2005.

RUMLEY AG, WOODWARD M, RUMLEY A, RUMLEY J, LOWE GDO: Plasma lipid peroxides: relationships to cardiovascular risk factors and prevalent cardiovascular disease. QJM 97: 809-816, 2004.

SACERDOTE A, WEISS K, TRAN T, NOOR BR, MCFARLANE SI: Hypertension in patients with Cushing's disease: pathophysiology, diagnosis, and management. Curr Hypertens Rep 7: 212-218, 2005.

SCHALKWIJK CG, STEHOUWER CDA: Vascular complications in diabetes mellitus: the role of endothelial dysfunction. Clin Sci 109: 143-159, 2005.

ŠKRHA J: Pathogenesis of angiopathy in diabetes. Acta Diabetol 40 (Suppl 2): S324-S329, 2003.

ŠKRHA J, HILGERTOVÁ J: Relationship of serum N-acetyl-beta-glucosaminidase activity to oxidative stress in diabetes mellitus. Clin Chim Acta 282: 167-174, 1999.

ŠKRHA J, PERUŠIČOVÁ J, ŠTOLBA P, STIBOR V, PÁV J: Comparison of N-acetyl-beta-glucosaminidase and albuminuria with clinical finding of microangiopathy in type I diabetes mellitus. Clin Chim Acta 166: 135-141, 1987.

ŠKRHA J, PRÁZNÝ M, HAAS T, KVASNIČKA J, KALVODOVÁ B: Comparison of laser-Doppler flowmetry with biochemical indicators of endothelial dysfunction related to early microangiopathy in Type 1 diabetic patients. J Diabetes Complications 15: 234-240, 2001.

ŠTULC T, KASALOVÁ Z, PRÁZNÝ M, VRABLÍK M, ŠKRHA J, ČEŠKA R: Microvascular reactivity in patients with hypercholesterolemia: effect of lipid lowering treatment. Physiol Res 52: 439-445, 2003.

VINCENT HK, TAYLOR AG: Biomarkers and potential mechanisms of obesity-induced oxidant stress in humans. Int J Obes 30: 400-418, 2005.

WITH N, MATHIESEN EB, AMIRAL J, VISSAC AM, HANSEN JB: Endothelial dysfunction and systemic inflammation in persons with echolucent carotid plaques. Thromb Haemost 96: 53-59, 2006.

YAGI H: A simple fluorimetric assay for lipoperoxide in blood plasma. Biochem Med 15: 212-216, 1976.

YVONNE-TEE GB, GHULAM RASOOL AH, HALIM AS, BDUL RAHMAN AR: Noninvasive assessment of cutaneous vascular function in vivo using capillaroscopy, plethysmography and laser-Doppler instruments: its strengths and weaknesses. Clin Hemorheol Microcirc 34: 457-473, 2006. 